\title{
Application of Response Surface Methodology for Determining Optimal Factors in Maximization of Maize Grain Yield and Total Microbial Count in Long Term Agricultural Experiment, Kenya
}

\author{
Wambua Alex Mwaniki ${ }^{1, ~ *, ~ K o s k e ~ J o s e p h ~}{ }^{2}$, Mutiso John², Mulinge Wellington ${ }^{3}$, Kibunja Catherine ${ }^{3}$, \\ Eboi Bramuel $^{1}$ \\ ${ }^{1}$ Department of Planning and Statistics, Ministry of Agriculture, Livestock and Fisheries, Nairobi, Kenya \\ ${ }^{2}$ Department of Mathematics and Computer Science, Moi University, Eldoret, Kenya \\ ${ }^{3}$ Kenya Agricultural and Livestock Research Organization, Nairobi, Kenya
}

Email address:

mwanikialex19@gmail.com (W. A. Mwaniki),mwaniki.alex@hotmail.com (W. A. Mwaniki)

${ }^{*}$ Corresponding author

\section{To cite this article:}

Wambua Alex Mwaniki, Koske Joseph, Mutiso John, Mulinge Wellington, Kibunja Catherine, Eboi Bramuel. Application of Response Surface Methodology for Determining Optimal Factors in Maximization of Maize Grain Yield and Total Microbial Count in Long Term Agricultural Experiment, Kenya. Science Journal of Applied Mathematics and Statistics. Vol. 5, No. 6, 2017, pp. $200-209$.

doi: 10.11648/j.sjams.20170506.12

Received: September 20, 2017; Accepted: October 8, 2017; Published: November 11, 2017

\begin{abstract}
The Agriculture sector is the main stay of the Kenyan economic development contributing over $70 \%$ of the Gross Domestic Product (GDP). The sector is faced with numerous challenges leading to frequent and recurrent food shortages. Declining maize grain yield is one among the major challenges that call for urgent interventions to address the looming food crisis in the country. Maize play a big role in the Kenyan food security and in most case lack of the same is taken to mean food insecurity. It is due the importance attached to the crop that a Long Term Agricultural Experiments (LTAE) was set up specifically to research on the Maize grain yield. Many paper published on the LTAE in the country are only single factors analysis and lack the application of Response Surface Methodology (RSM) approaches in solving challenges facing the low and declining maize grain yield $\left(y_{1}\right)$, total microbe population $\left(y_{2}\right)$ a crucial component of Soil Organic Matter (SOM) and their optimization. The focus of this paper therefore is the application of RSM in maize grain yield and total microbial population optimization. Specifically, the paper determined the most significant factors for maize grain yield and total microbial population (bacteria, fungi, actinomycetes, rhizobia), (screening phase of the paper), constructed of an efficient and appropriate experimental design for evaluating the optimal settings of maize yield and total microbial population count and determined univariate optimal settings for maize grain yield and total microbial population. The primary data was summarized from LTAE in National Agricultural Research Laboratories (NARL) in Kabete under the Kenya Agriculture and Livestock Research Organization (KALRO) and secondary data imputed for experimental points falling outside the set field experimental design points. Two treatment factors were identified as the most significant treatment factors (Farm Yard Manure (FYM) and Nitrogen and Phosphorus (NP)) at their low levels and Circumscribed Central Composite Design (CCCD) with two star points as the most efficient design. CCCD passed most optimal criteria of DAET. Univariately, optimal setting for maize grain yield was realized at $3.8 \times 10^{3} \mathrm{~kg} / \mathrm{ha}$ and that of the total microbial population at $3.6 \times 10^{6}$ count. The study confirmed that it was possible to optimize the input treatment factor that lead to the optimization of both maize grain yield and maintaining maximal total microbial population count at its optimal levels.
\end{abstract}

Keywords: Response Surface Methodology, Long Term Agricultural Experiments, Univariate Optimization, Circumscribed Central Composite Design 


\section{Introduction}

Agricultural experiments are key undertaking in the development of most countries. Over the years the growth of scientific agricultural experiments has transformed the agricultural sector, [17]. In agricultural practices, experimentation occupies a crucial undertaking in the improvement of farming practices, [24]. The development of various forms of scientific experiments on crop improvement has led to considerable advancement in finding the optimal agricultural conditions for crop production and the same applies to maize production. Seeking the optimal input and output setting for maize grain yield and total microbial population count is a critical experimental undertaking that solves the food insecurity and hence the decreasing incomes to small scale farmers. Such experimental agenda, give experimenter adequate range of treatment factors (fertilizer, seed among others) to balance for optimum response (yield) in both maize grain yield and total microbes. This has also been motivated by the need to produce more food to feed the increasing world population and also to strike a balance between producing more food and the food safety concept, [8]. Agriculture sector is key in Kenyan Economy, [13].

Long Term Agricultural Experiments (LTAE) is experiments developed to run for a long time and are mainly used to monitor faming systems and soil fertility loss over time.

\subsection{Why Response Surface Methodology (RSM)}

The increased demand for robust experimental designs across various scientific disciplines has resulted to RSM receiving considerable attention. RSM is concerned with the modeling of one or more response variables using several explanatory variables. RSM is an important concept in the design of experiments as it has continued to provide solution in many fields including agriculture. The initial concept on RSM was introduced by Box and Wilson in 1951, [1]. The number of experimental problems that can be solved using RSM has tremendously increased overtime.

\subsection{RSM in Agricultural Experiments}

Agricultural field experimentation has evolved over time employing different experimental concepts in solving the challenging aspects. Documented available studies in LTAE have studied single treatment factor at a time which could be misleading in the long run, [23]. The properties of RSM offer a feasible near solution to such due to its robustness and approach. This paper utilizes the RSM advancements made in industrial experiments and in the process optimization to solve challenges in agricultural experimentation and more specifically in LTAE in seeking feasible solutions in soil fertility management options for the small-scale farmers in Kenya who depend on maize crop for their livelihood.

\subsection{Optimization Process}

In statistics, optimization is the process of making a design as functional and effective as possible. The search for optimal settings in crop (especially in maize grain yield) production naturally presents the need for more than one treatment factor to be optimized (minimized/maximized). Agricultural experiments like any other multi-objective (more than one optimization goal) optimal seeking experiments and systems is expected to balance several production factors (inputs) for benefits (outputs) to ensure that food safety for the future generation is assured and save, [8].

\subsection{Challenges Facing Maize Production in Kenya}

The main challenge associated with the declining maize grain yields and total microbial population count (measured using Soil Organic Matter (SOM)) has been linked to the declining soil fertility. Soil degradation is a widespread problem. Resource poor, subsistence farming and low-inputs agricultural practices are among the major factors that push further the soil degradation, [5]. These have led to; low productivity, low income, rural-urban migration, household and national food insecurity, [7].

\subsection{The Problem}

Continuous crop production in the various agricultural LTAE including maize experiments trials has pointed out the decline in essential soil nutrients either through erosion and/or through nutrient loss by crop uptake being the main cause. These has resulted to progressive low maize grain yields, low levels of the optimal total microbial population count and high production costs for sustained production of the crop. LTAE in National Agriculture Research Laboratory (NARL) on soil fertility maintenance concluded that a set of critical treatment factors existed below which it became extremely difficult to maintain maize and beans yields, [10]. To address these changes therefore, different scientific, agronomic and statistical modeling are of paramount value for responding to this noble recommendations to avert food and nutrition insecurity in the country.

\subsection{Scope}

The paper considered two response variables, maize grain yield $\left(\mathrm{y}_{1}\right)$ and the total microbial population count $\left(\mathrm{y}_{2}\right)$. The paper presents an analysis of LTAE in KALRO and used sample years (based on data availability and data normalcy) data for building optimal models for maize yield and total population count. Maize grain yield $\left(\mathrm{y}_{1}\right)$ was measured and reported in $\mathrm{kg} / \mathrm{ha}$. The total microbial population $\left(\mathrm{y}_{2}\right)$ was used as an indicator and measure of soil fertility extracted as sum of the total common microbes that included bacteria, fungi, actinomycetes and rhizobia. Optimalities for both treatment factors and response variables $\mathrm{y}_{1}$ and $\mathrm{y}_{2}$ were determined. 


\subsection{A Review of Soil Fertility Studies}

Soil fertility management agricultural experiments have been undertaken by both the developed and the developing counties with the aim of understanding the effects of soil fertility on crop yields. In East Africa such initiatives started back in 1930's to address issues of soil fertility through the combination of vegetative fallows and animal manure [34] (Kibunja, 2007). Most of the studies point out to a one dimensional soil fertility maintainance and less use of robust statistical analysis and RSM approaches.

\subsection{Screening Experiments}

Screening designs are normally performed at the beginning of an investigation when the experimenter intends to characterize a process. In this case, characterizing translated to determining the main treatment factors and investigating the changes of the response by varying each factor [51] (Montgomery, 2009). This identification of the critical process treatment factors can be very useful for later optimization processes because only a subset of the treatment factors have to be considered. Factor screening also play a big role in large experiments with many treatment factors to optimize or consider.

An experiment can have a large number of factors but usually only a handful of the factors are important and significant. A screening experiment employs a design of economical run size to identify the most important treatment factors [13] (Cheng \& Wu, 2001). Such experiments are of $1^{\text {st }}$-order design fractional factorial designs or PlackettBurman designs with intensive study of the response surface, typically with fewer factors and over a smaller region. $2^{\mathrm{n}-\mathrm{k}}$ designs are most commonly used for screening stage [24] (George, Hunter, \& Hunter, 2005).

Another useful approach in the identification of key factors is the use of Pareto plots that graphically represents the most important treatment factors in their absolute terms. The plots are weights of the different factors in descending order with less important factors forming the tail of the plot (lower weights). In such plots care is called for as for qualifying a factor that has a significant interaction(s) as in no case that a factors' main effect is rejected and its interaction is qualified.

The goal at this stage (screening) is to find the real important inputs (factors) among the many inputs/output factors that may be changed in a real experiment. Real-world processes are driven by only a few factors, the others being relatively unimportant. With screening designs, responses are taken only for a small fraction of the total possible combinations to reduce the number of runs and hence cost [71] (Wass, 2010).

Specialized designs require screening when a number of factors are too large for even a highly fractionated design [31] (Kelton, 1999). Various screening analyses can be utilized with the most conventional method based on main effects estimation or the Analysis of Variance (ANOVA). A factor is identified as important if its main effects are significant, [2].

\subsection{Constructing Robust and Efficient Experiments Designs}

Robust Designs of Experiments (DoE) have been constructed to guide the development of various modern experiments. These designs have an extensive statistical element incorporated making them extensively reliable compared to the earlier methods. With the enhanced procedures, DoE have attracted many diverse applications in research work. Most of the initial DoE involved varying of one factor only at a time which presented considerable challenges. Orthogonality property in DoE was later introduced by Taguchi in early 1950's, [26]. However, it was until 1950 that a break through study was carried out by Cox and Cochran that have since been the corner stone for DoE development and advancement, [3]. Despite the above earlier studies that optimized single factors independently, the current paper has extended the concept and optimized two factors simultaneously.

\subsection{Response Surface Methodology (RSM)}

RSM is a collection of statistical and mathematical techniques that are useful for developing, improving and optimizing experimental and industrial processes. RSM has the ability to produce an approximate function even with a smaller amount of data, [25]. The approach is also easy to use and apply even with minimal knowledge of the underlying process.

In real-world RSM application problems, it is quite common that several responses are of interest, [16]. In RSM setting, the experimenter attempts to find the optimal setting for the input variables that maximizes (or minimizes) the response, [21].

RSM methodology was introduced by Box and Wilson in 1951, [1] by suggesting the adoption and use of the $1^{\text {st }}$-degree polynomial in the estimation of response variable. For typical RSM, [21], data from experimental design is used to build a model for approximating the relationship between the outputs $\left(\mathrm{y}_{\mathrm{i}}\right)$ and inputs $\left(\mathrm{x}_{\mathrm{i}}\right)$ variables, upon which the optimization is undertaken, [19]. In most cases the univariate optimization has been used in which case only one response variable is optimized.

\subsection{Response Surface Methodology in Agricultural Experiments}

Mead and Pike in 1975, [18] study was the first to review the role of RSM in agriculture, however, the study ended up recommending the use of non-linear model to address and accommodate biological data. More insights of RSM in agriculture were presented by Edmondson in 1991, [4], in the study that gave crucial findings of RSM in greenhouse experiments, [17]. The study further, presented valuable knowledge on the use of RSM within the agricultural research and experiments as opposed to an industrial setting. 


\section{Method}

\subsection{Screening Experiment}

This formed an initial step that involved analysis of all the six (6) treatment factors (Control, R, FYM1, FYM2, $\mathrm{N}_{1} \mathrm{P}_{1}$ and $\mathrm{N}_{2} \mathrm{P}_{2}$ ) that were distributed into 4 blocks (Block I, II, III and IV) (Annex I). This enabled screening of the most important treatment factors to form inputs for a robust experimental stage and experimentation purpose.

The screening phase analysis was based on $1^{\text {st }}$ - order regression model (equation 1) followed by a more intensive study of the response surface with a fewer treatment factors and over a smaller region based on $2^{\text {nd }}$-order design (for testing the only significant interaction factors).

$$
y=\beta_{0}+\beta_{1} F Y M+\beta_{2} N P+\beta_{12} F Y M * N P+\varepsilon
$$

\subsection{Design of Experiments (DoE) for the Study}

DoE was used to find out the cause-and-effect relationship between input (FYM and the mineral fertilizers) and output (maize grain yield and total microbial population).

Several treatment factors that affected simultaneously the maize grain yield and total microbial population were given more weight especially the main effects (isolated factor) and the interaction effects. The simplest design tested was represented by a $2^{2}$ factorial designs. Two levels of each treatment factor was denoted as "low" and "high" symbolic presented as "-" at low level and as "+" at high level. For $2^{2}$ yielded 4 runs for full factorial at their main effect was represented in Figure 1.

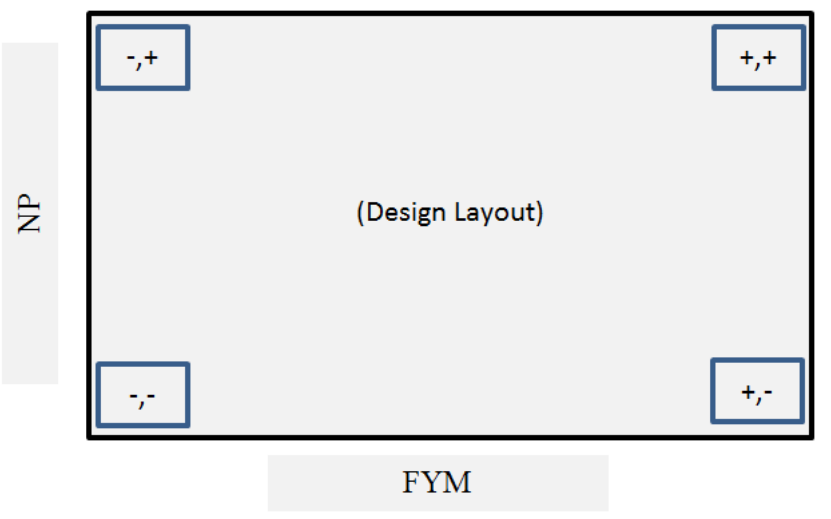

Figure 1. A $2^{2}$ Factorial Design Layout.

The general model for full factorial that represented Figure 1 was presented as (2) and a general model (3).

$$
y=\beta_{0}+\beta_{1} F Y M+\beta_{2} N P+\beta_{12} F Y M * N P+\varepsilon
$$

and

$$
y=\beta_{0}+\beta_{1} F Y M+\beta_{2} N P+\beta_{11} F Y M^{2}+\beta_{22} N P^{2}+\beta_{12} F Y M * N P+\varepsilon
$$

To improve on the above design and arrive at a precise result the study applied a Central Composite Design (CCD) with an embedded factorial design with centre point and an augmented "star points" for curvatures estimation.

Choosing a suitable experimental design was an important step in investigating factors that influenced the response variables (maize grain yield $\left(\mathrm{y}_{1}\right)$ and total microbial population $\left.\left(\mathrm{y}_{2}\right)\right)$. The paper used optimal criteria to evaluate the three CCD designs ( $2^{2}$ - factorial, $\mathrm{CCD}$ and the CCCD) and the design with a combination of best optimal criteria was chosen. D-, A-, E-, T-Optimalities (DAET) was applied in this step.

\subsection{Optimal Settings for Maize Grain Yield and Total Microbial Population Count}

Optimization was achieved by undertaking the following steps:-

1. Screening that involved the determination of factors that influence the outcome variables;

2. Improvement of the process that involved approaches in search of optimum by repeated change of input factor(s) settings and

3. Determining the optimum of the input factors and the optimal settings of response factors (maize yield and total microbial population) settings.

The surface is represented by the response surface equation,

$$
\eta=f\left(\mathrm{x}_{1}, \mathrm{x}_{2}\right)
$$

In the search of optimal region, the following steps were undertaken;

Step I: Finding a suitable approximation for $\mathrm{y}=\mathrm{f}(\mathrm{x})$ using Least Square Method (LSM) in a low-order polynomial;

Step II: Moving towards the region of optimum (climbing/descending the hill) and

Step III: When curvature was found, locating a new approximation for $\mathrm{y}=\mathrm{f}(\mathrm{x})$ (generally a higher order polynomial);

Step IV: Performing the response surface analysis proper and

Step V: Optimization of the process for $\mathrm{y}_{1}$ and $\mathrm{y}_{2}$.

For screening and for steepest ascent, the $1^{\text {st }}$-order model was used for each of the response variables ( $\mathrm{y}_{1}$ and $\mathrm{y}_{2}$ ) independently. Equation (5) represents maize while (6) represents total microbes;

$$
y_{1}=\beta_{0}+\sum_{i=1}^{k} \beta_{i} x_{i}+\varepsilon
$$

and

$$
y_{2}=\beta_{0}+\sum_{i=1}^{k} \beta_{i} x_{i}+\varepsilon
$$

The 2 nd - order was further estimated using the equation (7).

$$
y=\beta_{0}+\sum_{i=1}^{k} \beta_{i} x_{i}+\sum \sum_{i<j}^{k} \beta_{i j} x_{i} x_{j}+\varepsilon
$$




\subsection{Optimization in Case of Single ( $Y_{1}$ and $\left.Y_{2}\right)$ Response Experiment}

This was achieved using the following methods;

1. Graphically (through contours in case of 2 factors) and

2. Analytically (for validating the method 1 ).

\section{Results}

\subsection{Significant Treatment Factors for the Maize Grain Yield $\left(Y_{1}\right)$}

From the regression analysis three factors levels significantly explained the maize grain yield $\mathrm{N}_{1} \mathrm{P}_{1}+\mathrm{FYM}_{1}\left(\mathrm{x}_{1}\right)$, NIL and NIL+R and $\mathrm{FYM}_{1}$ (in the intercept) all with pvalue $<0.001, R^{2}=96.4 \%$ and adjusted $R^{2}=94.6 \%$. However, treatments with NIL (controls) had a negative (-ve) influence on the maize grain yield (Annex II). The treatments were also significant ( $p$-value $<0.001)$ while that of blocks were not statistically significant. The intercepts was large enough to be ignored and therefore it was retained for modeling the maize grain yield. The blocks effects were not significant which was due to their insignificance from the initial descriptive plots. This was an encouraging result as blocks were only intended for local control and further random error. The largest positive effects on the maize grain yields were realized with $\mathrm{N}_{1} \mathrm{P}_{1}+\mathrm{FYM}_{1}, \mathrm{~N}_{1} \mathrm{P}_{1}+\mathrm{FYM}_{1}+\mathrm{R}$ and $\mathrm{FYM}_{1}+\mathrm{R}$ treatments while the greatest negative effects were from NIL, NIL+R treatments. This is a clear indication that the combination of chemical fertilizers and the FYM had better yields for maize.

Further, the study evaluated the model adequacies which were met.

\subsection{Significant Factors for Total Microbial Population Count (y2)}

The $1^{\text {st }}$-order model for the total microbial population count did not reflect significant $(p>0.05)$. This led to the undertaking of a full model, normally proposed in such cases to get the significance in higher levels models (Annex III).

Only interaction between, NIL: Block-II and $\mathrm{FYM}_{1}$ : R: Block-II turned significant in the full model. This indicated that their main factors need to be considered in the optimization stage as primary treatment factors. This implies that NIL (control) and $\mathrm{FYM}_{1}+\mathrm{R}$ were important. R-square improved from $24 \%$ to $69 \%$ from the reduced model to the full model $\left(2^{\text {nd }}-\right.$ order $)$.

\subsection{Efficient and Appropriate Experimental Design for Optimal Setting for Maize Yield and Total Microbial Population}

Efficient design for the two responses variables (maize and total microbes) that lead to the optimal region step by step is proposed.

The baseline (centre point - $(0,0)$ ) was taken as the usual farmers practice (status quo) $\mathrm{FYM}_{1}$ and $\mathrm{N}_{1} \mathrm{P}_{1}$ and also the same factors that were statistically significant in the prediction of the two response factors. To represent the same mathematically, the study used coded values to link the two (coded and natural values). The responses were computed from the average of the different levels of the factor treatments. To measure the model disturbances, crop residues were added in the design as they were likely to affect the maize yields and the subsequent treatment levels. The estimated responses were arrived at by averaging yields and microbial population count from the different factor levels using statistical intra and extra-polation procedures. The computed values were later compared with the model estimated values to assess model fit and to map the next design points.

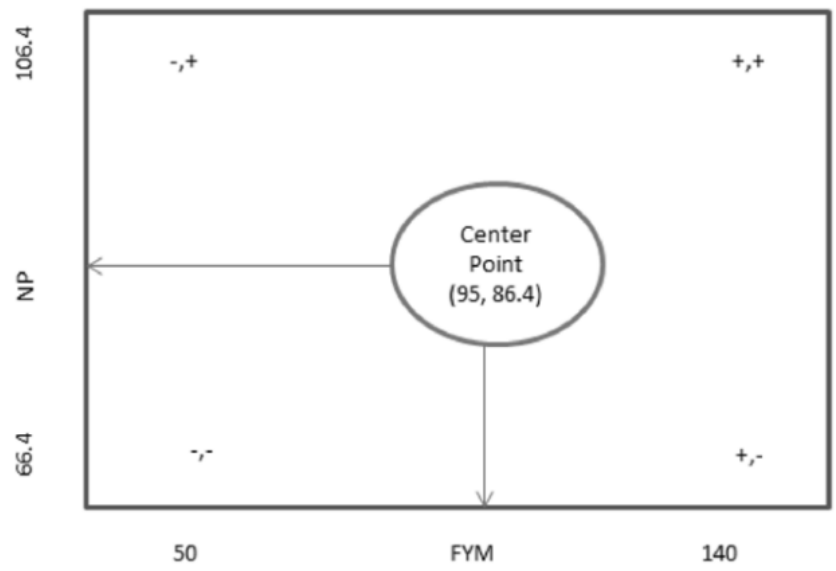

Figure 2. Design 1 Indicating the Link between Coded and Natural Values.

Using figure 1, the design points and model in Table 1 and 2 were generated.

Table 1. Design I Layout for the Treatment Factors and the Corresponding to the Imputed Values for Responses.

\begin{tabular}{|c|c|c|c|c|c|c|c|}
\hline Experiment & FYM & NP & fym & np & maize yield & Total Microbes & Model \\
\hline Current Point & 95 & 86.4 & 0 & 0 & $3,259.0$ & $3,252,158.5$ & 1 \\
\hline 1 & 50 & 66.4 & -1 & -1 & $3,239.0$ & $3,095,105.0$ & 1 \\
\hline 2 & 50 & 106.4 & -1 & 1 & $3,264.0$ & $3,023,695.0$ & 1 \\
\hline 3 & 140 & 66.4 & 1 & -1 & $3,275.0$ & $3,480,621.0$ & 1 \\
\hline 4 & 140 & 106.4 & 1 & -1 & $3,300.0$ & $3,409,212.0$ & 1 \\
\hline
\end{tabular}

Table 2. Design 1 Model for Maize Yield $\left(y_{1}\right)$

\begin{tabular}{lllll}
\hline Parameter & Estimate & se & t-value & p-Value \\
\hline Intercept & 3269.5 & 0 & 5.5 & $<0.001$ \\
fym & 18 & 0 & 2.7 & $<0.001$ \\
np & 12.5 & 0 & 1.91 & 0.001 \\
fyp:np & 0 & 0 & 0.02 & 0.988 \\
\hline
\end{tabular}


With the corresponding model given by;

$$
\hat{y}_{1}=3.3 \times 10^{3}+18 f y m+12.5 n p+0 \text { fym }: n p
$$

For the total microbial population count the model became

$$
\hat{y}_{2}=3.3 \times 10^{6}+1.9 \times 10^{5} \text { fym }-3.6 \times 10^{3} n p+0.25 \text { fym }: n p
$$

Giving;

Table 3. Design 1 Contour Plots for Total Microbial Population.

\begin{tabular}{lllll}
\hline Parameter & Estimate & se & t-value & p-Value \\
\hline Intercept & 3252158 & 0.17 & 18776345 & $<0.001$ \\
fym & 192758.3 & 0.19 & 995399.3 & $<0.001$ \\
np & -35704.8 & 0.19 & -184379 & $<0.001$ \\
fyp:np & 0.25 & 0.11 & 2.24 & 0.2677 \\
\hline
\end{tabular}

The interaction between fym and np (fym:np) was very small relative to the main effects coefficients (large values) and it is also not significant; dropping this, the new model for microbial population as;

$$
\hat{y}_{2}=3.3 \times 10^{6}+1.9 \times 10^{5} \text { fym }-3.6 \times 10^{3} \mathrm{np}
$$

For the steepest ascent, the two equations, indicates that moving from low levels of $\mathrm{FYM}_{1}$ to higher levels of $\mathrm{FYM}_{1}$ (in coded values), the maize yield increases by $18 \mathrm{~kg} / \mathrm{ha}$ and moving from low level for $\mathrm{N}_{1} \mathrm{P}_{1}$ to the higher levels $\mathrm{N}_{1} \mathrm{P}_{1}+\mathrm{R}$ the maize yield increases by $12.5 \mathrm{~kg} / \mathrm{Ha}$. Similarly, moving from low levels of $\mathrm{FYM}_{1}$ to higher levels of $\mathrm{FYM}_{1}$, the microbial population increases by $1.9 \times 10^{5}$ and moving from low level for $\mathrm{N}_{1} \mathrm{P}_{1}$ to the higher levels of $\mathrm{N}_{1} \mathrm{P}_{1}$ the microbial population count decreases by $3.6 \times 10^{4}$.

This was expected from the descriptive analysis that portrayed that the addition of artificial fertilizers had decreasing effects on the microbial population count. This also indicated that maize grain yields registered improved performances when the both treatments are at their high factor levels. This assertion is further portrayed in the contour plots for the two response variables
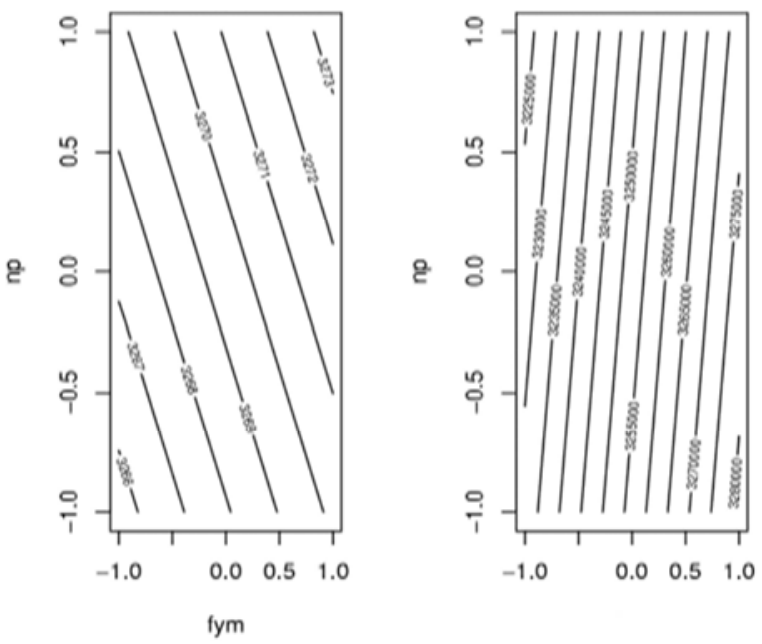

Figure 3. Design 1 Contour Plots for Maize Yield and Total Microbial Population.
The 3 designs criteria proposed section 3, when applied gave D-, E- and A- optimality values as in Table 4. With these results the study concluded that a Circumscribed Central Composite Design (CCCD) design was the most appropriate. Using the CCCD as the efficient design for the maize grain yield and total microbial population count with two star points the response factors are generated

Table 4. D. A. E. Tfor the 3 Designs.

\begin{tabular}{lllll}
\hline Optimality & Factorial & FCD & CCCD & Criterion \\
\hline $\mathrm{D}$ & 80 & 182.25 & 442.4 & Larger the better \\
$\mathrm{A}$ & 0.7 & 0.71 & 0.4 & smaller the better \\
$\mathrm{E}$ & 0.25 & 0.22 & 0.17 & smaller the better \\
$\mathrm{T}$ & 7.5 & 9.5 & 7.7 & smaller the better \\
\hline
\end{tabular}

\subsection{Estimating the Response (Outcome) Variables from the Best Design}

Having established the appropriate best design for the experiment, the results reported from the main experiment were used to estimate the maize grain yield and total microbial population count using both extra and intrapolation approaches at various treatment factor levels outside the LTEA formulation. This was deemed necessary as efficient design called for extra design points not within the LTEA. For instance, at center point $(0,0)$ the maize yields and total microbial population were calculated using simple average. For other design points, we used the extrapolation and simulation formula model that gave.

Table 5. Estimation of Response Values outside the normal LTAE design points.

\begin{tabular}{lll}
\hline Experimental Point & Maize Yield $\left(\mathbf{y}_{\mathbf{1}}\right)$ & Microbial Population $\left(\mathbf{y}_{2}\right)$ \\
\hline 0,0 & $(3202+3226) / 2$ & $(4126373+2063837) / 2$ \\
$-1,-1$ & Extrapolation $_{1}$ & Extrapolation $_{2}$ \\
$-1+1$ & Extrapolation $_{3}$ & Extrapolation $_{4}$ \\
$+1,+1$ & Extrapolation $_{5}$ & Extrapolation $_{6}$ \\
$0,+1.41$ & Extrapolation $_{7}$ & Extrapolation $_{8}$ \\
$-1.41,0$ & Extrapolation $_{9}$ & Extrapolation $_{10}$ \\
$+1.41,1$ & Extrapolation $_{11}$ & Extrapolation $_{12}$ \\
$0,-1.41$ & Extrapolation $_{13}$ & Extrapolation $_{14}$ \\
\hline
\end{tabular}

The extrapolation formulas were used in estimating the response values outside the experiment and the resulting output. The resultant data was used in the next testing determining the optimal inputs that gave the optimal outputs value. The extrapolation values of the response values were determined using equation (11).

$$
y_{1}+\frac{x-x_{2}}{x_{2}-x_{1}}\left(y_{2}-y_{1}\right)
$$

\subsection{Determining the Optimal Settings for Maize Grain Yield and Total Microbial Population Count}

The optimization for this section was derived for maize yield and total microbial population count response variable independently using results from the Table 6 . 
Table 6. Estimated Data for CCCD with star points.

\begin{tabular}{lllll}
\hline partten & fym & np & yield & microbial \\
\hline+- & 1 & 1 & 3264 & 3095105 \\
-+ & -1 & 1 & 2160.11 & 2433104 \\
00 & 0 & 0 & 3264 & 3095105 \\
-- & -1 & -1 & 2113.17 & 2003824 \\
A0 & 1.41 & 0 & 4211.79 & 3470620 \\
00 & 0 & 0 & 3264 & 3095105 \\
++ & 1 & 1 & 4414.83 & 3689516 \\
$0 \mathrm{~A}$ & 0 & 1.41 & 4744.46 & 4148661 \\
$0 \mathrm{a}$ & 0 & 1.41 & 3018.81 & 2352240 \\
$\mathrm{a} 0$ & -1.41 & 0 & 2269.23 & 2204914 \\
\hline
\end{tabular}

The real values are for farm yard $=120.65 \mathrm{~kg} / \mathrm{ha}$ equivalent to 13.3 tons/ha of fym. This should contain an estimated $64.34 \mathrm{~kg} \mathrm{~N}$ and $32.17 \mathrm{~kg} \mathrm{P}$ at the optimal region. For $\mathrm{np}$ the real values are $11.6 \mathrm{~kg} / \mathrm{ha}$ equivalent to almost $1.5 \mathrm{bags} / \mathrm{ha}$. The optimal values for fym and $\mathrm{np}$ are $120.65 \mathrm{~kg} / \mathrm{ha}$ and 11.6 $\mathrm{kg} / \mathrm{ha}$ that yields to the maximal yield of $3.80 \times 10^{3}$. This gave the contour and response surface plots in Figures 4-8.

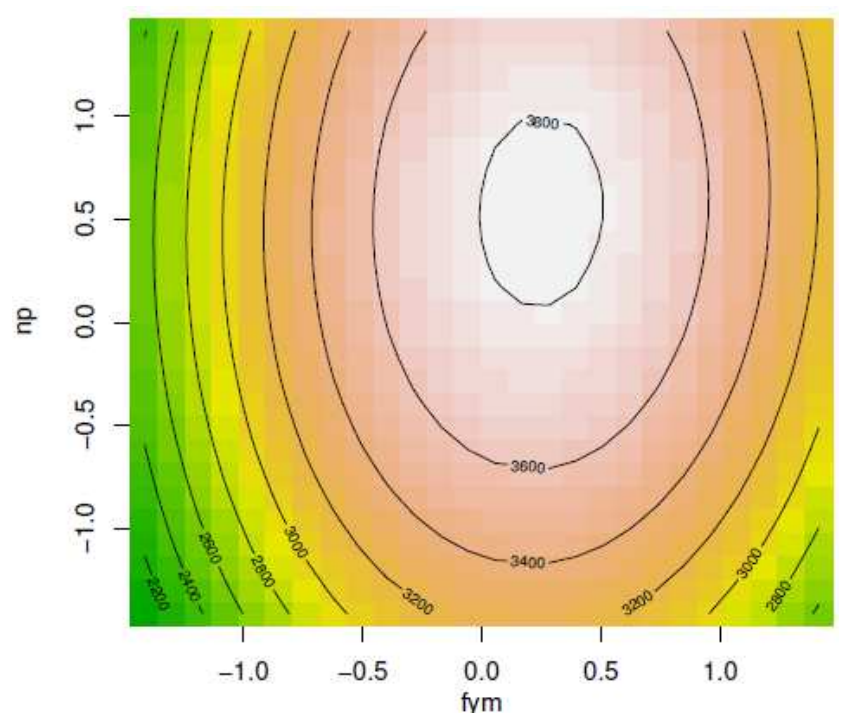

Figure 4. Contours at the Optimal Region for Maize Yield $\left(y_{1}\right)$.

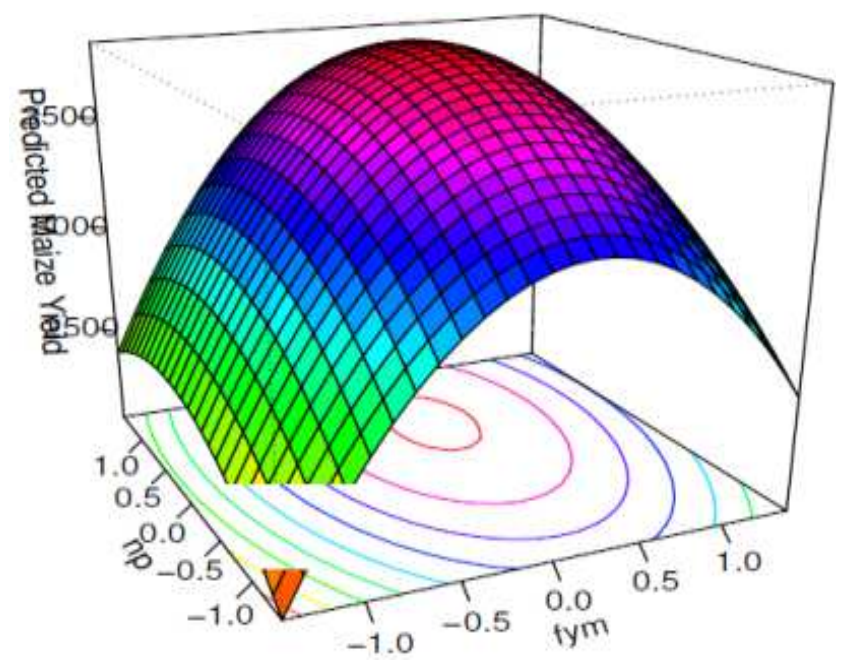

Figure 5. Response Surface Plot for Maize Yield $\left(y_{1}\right)$.
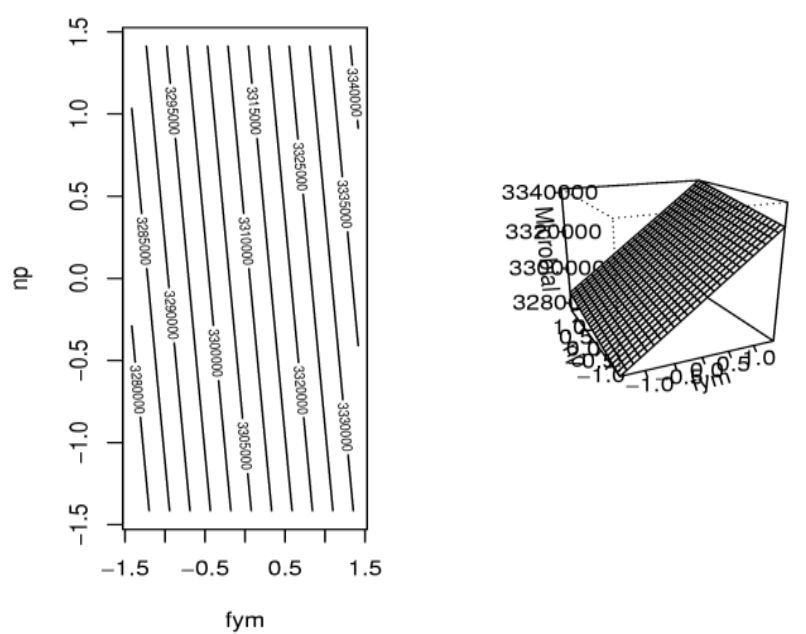

Figure 6. Contours and Response Surface for model total microbial population.

The $2^{\text {nd }}$ model fitted the data well and were used for searching the path of steepest ascent.

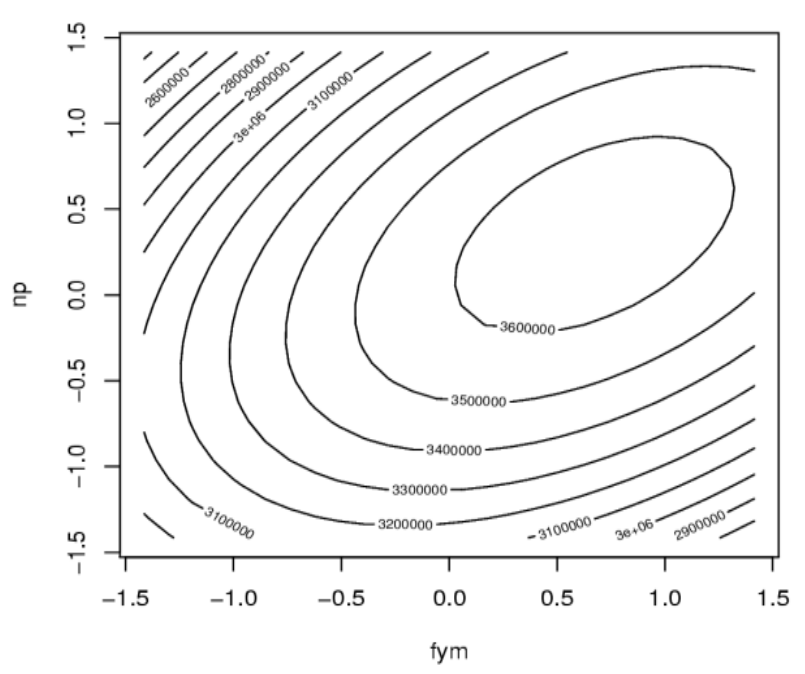

Figure 7. Steepest Ascent for Total Microbial population ( $\left.y_{2}\right)$.

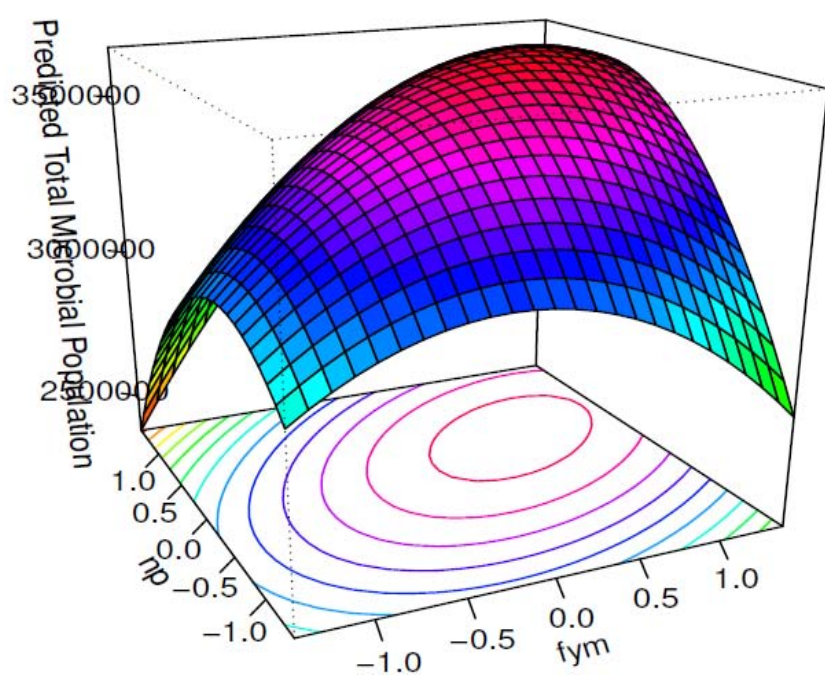

Figure 8. Response Surface plot for Microbial Population ( $\left.y_{2}\right)$. 
Solving this gives coded values, the real values are for farm yard $=92.75 \mathrm{~kg} /$ ha equivalent to 10.2 tons $/$ ha. This will contain an estimated $76.82 \mathrm{~kg} \mathrm{~N}$ and $15.93 \mathrm{~kg} \mathrm{P}$ at the optimal region. For $\mathrm{np}$ the real values are $12.4 \mathrm{~kg} / \mathrm{ha}$ equivalent to almost bags $5.4 \mathrm{~kg} / \mathrm{ha}$ of $\mathrm{N}$ and $7.00 \mathrm{~kg} / \mathrm{ha}$ of $\mathrm{P}$.
Under these settings the optimal microbial population was estimated at $3.6 \times 10^{6}$.

Table 7 below gives a summary of the univariate optimization achieved that will led to the optimal levels of the maize grain yield and total microbes population count.

Table 7. Summary of Univariate Optimalities, $y_{1}$ and $y_{2}$.

\begin{tabular}{llll}
\hline fym & np & optimal yield & optimal microbial population \\
\hline $120.65 \mathrm{~kg} / \mathrm{ha}$ & $64.34 \mathrm{~kg} / \mathrm{ha}$ & 3.8103 & - \\
$92.75 \mathrm{~kg} / \mathrm{ha}$ & $12.5 \mathrm{~kg} / \mathrm{ha}$ & - & $3.6 \times 106$ \\
\hline
\end{tabular}

\section{Discussions}

The largest positive effects on the maize yields were realized with $\mathrm{N}_{1} \mathrm{P}_{1}+\mathrm{FYM}_{1}, \mathrm{~N}_{1} \mathrm{P}_{1}+\mathrm{FYM}_{1}+\mathrm{R}$ and $\mathrm{FYM}_{1}+\mathrm{R}$ treatments while the greatest negative effects were from NIL, $\mathrm{NIL}+\mathrm{R}$ treatments. This is a clear indication that combination of chemical fertilizers and the FYM produces better yields for maize. These results are in consistent with earlier studies in LTEA and in Embu, Kenya that concluded that use of the inorganic fertilizers had higher response to high yields when supplemented with the FYM that retained the SOM an able condition of multiplication of the microbe.

From the two $1^{\text {st }}$-order models selection a parsimonious set of treatment factors were identified for the subsequent phase of experimental design for optimizing both the responses. Considering the significant factors and impact of the factors and through informed consultation with the LTEA experts on the commonly used practices by small-scale farmer in the Country and also due to its significance size, the $\mathrm{FYM}_{1}+$ $\mathrm{N}_{1} \mathrm{P}_{1}$ treatment factor was identified for optimizing the two responses (Maize yield and the total microbial population count). These include combination of the FYM (organicmanure application of 5 ton/Ha "boma" manure (about $75 \mathrm{~kg}$ $\mathrm{N}$ and $20 \mathrm{~kg} \mathrm{P}$ )) and the use N1P1 (chemical fertilizers - N1 $60 \mathrm{~kg} \mathrm{~N} / \mathrm{Ha}$ as Calcium Ammonium Nitrate (CAN), P1-26.4 $\mathrm{kg} / \mathrm{ha} \mathrm{P}$ as Triple Superphosphate (TSP)). The current practice for the treatment factors were taken as the baseline (center points, $(0,0))$ during the design of the experiments simulation and extrapolation procedure. The significant treatment factors FYM and NP selected were simulated to assess the possible levels for MOO maize yield and the total microbial population count.

\section{Conclusions}

It was evident that the maize yields from the LTEA were experiencing yields decline over years despite the continuous soil management option practices. The maize yields had declined to lows of about $2,100 \mathrm{~kg} / \mathrm{ha}$ in some treatments/soil management options. This calls for an integrated reversal approach in the retention of soil fertility. These points to a possible conclusion that the current operating soil fertility options are not optimal for the future soil fertility retention and for sustained maize yields.

Two treatment factors were isolated during the screening phase as the most significant and important treatment factors from a possible range of input and controllable factors. These were farm yard manure $\left(\mathrm{FYM}_{1}\right)$ and chemical fertilizers at level $\mathrm{N}_{1} \mathrm{P}_{1}$ at their lower levels. The two treatment factors significantly explained the maize yield and total microbial population. These two treatment factors were important in for ensuring the optimal maize yields while retaining the required threshold for total microbial population.

The study established that using the CCCD within the CCD with two star experimental points provided the best efficient and appropriate design for the MRSM and MOO in maize yield and total microbial population count.

The univariate optimal of maize yield and total microbial population count where higher compared to the multi-objective optimal that presented lower levels of both yield and microbial population. This is a confirmation that optimization of a single variable at a time can provide misleading conclusions and hence multi-response optimization offers the best solutions in cases were more than one factors of interest to the experimenter/Decision Maker (DM) are considered.

\section{Appendix}

\section{Appendix I: Treatments Factors}

\begin{tabular}{|c|c|c|c|c|}
\hline Variable & Variable.Type & Description & Derivation.of.the.Variable & Optimization.Goal \\
\hline Yield $\left(\mathrm{Y}_{1}\right)$ & Response & Achieved yield & Yield from the soil management & Maximum \\
\hline Microbial Population $\left(\mathrm{Y}_{2}\right)$ & Response & $\begin{array}{l}\text { Bacteria, Fungi } \\
\text { Actinomycetes, Rhizobia }\end{array}$ & Total microbe & Maximum \\
\hline Control $\left(\mathrm{x}_{1}\right)$ & Dependent & Controlled input & & \\
\hline Control $+\mathrm{R}\left(\mathrm{x}_{2}\right)$ & Dependent & Controlled input & & \\
\hline $\mathrm{FYM}_{1}+\mathrm{R}\left(\mathrm{x}_{3}\right)$ & Dependent & Controlled input & & \\
\hline $\mathrm{N}_{1} \mathrm{P}_{1}\left(\mathrm{x}_{4}\right)$ & Dependent & Controlled input & & \\
\hline $\mathrm{N}_{1} \mathrm{P}_{1}+\mathrm{R}\left(\mathrm{x}_{5}\right)$ & Dependent & Controlled input & & \\
\hline $\mathrm{N}_{1} \mathrm{P}_{1}\left(\mathrm{x}_{6}\right)$ & Dependent & Controlled input & & \\
\hline $\mathrm{N}_{1} \mathrm{P}_{1}+\mathrm{FYM}_{1}\left(\mathrm{x}_{7}\right)$ & Dependent & Controlled input & & \\
\hline $\mathrm{N}_{1} \mathrm{P}_{1}+\mathrm{FYM}_{1}+\mathrm{R}\left(\mathrm{x}_{8}\right)$ & Dependent & Controlled input & & \\
\hline
\end{tabular}


Appendix II: Model 1 for Maize Yield $\left(y_{1}\right)$

\begin{tabular}{rrrrr}
\hline Parameter & Estimate & Std. Error & $\mathrm{t}$ value & $\operatorname{Pr}(>|\mathrm{t}|)$ \\
\hline (Intercept) & $3,302.0000$ & 130.1283 & 25.37 & $<0.001$ \\
FYM1+R & 74.7125 & 99.7414 & 0.75 & 0.4621 \\
N1P1 & 8.5056 & 99.7554 & 0.09 & 0.9329 \\
N1P1+FYM1 & 565.0319 & 99.7554 & 5.66 & $<0.001$ \\
N1P1+FYM1+R & 182.7125 & 99.7414 & 1.83 & 0.0812 \\
N1P1+R & -111.7444 & 99.7554 & -1.12 & 0.2753 \\
NIL & -1340.2181 & 99.7554 & -13.44 & $<0.001$ \\
NIL+R & -658.5375 & 99.7414 & -6.60 & $<0.001$ \\
Block II & -6.8500 & 153.9698 & -0.04 & 0.9649 \\
Block III & -57.0224 & 154.1145 & -0.37 & 0.7151 \\
Block IV & 63.8724 & 154.1145 & 0.41 & 0.6827 \\
\hline
\end{tabular}

Appendix III: Model for Treatment Factors for Microbial Population (y $y_{2}$

\begin{tabular}{rrrrr}
\hline Parameter & Estimate & Std. Error & $\mathrm{t}$ value & $\operatorname{Pr}(>|\mathrm{t}|)$ \\
\hline (Intercept) & 3966945.0000 & 2621550.5784 & 1.51 & 0.1451 \\
FYM1+R & 583301.8500 & 2009380.4688 & 0.29 & 0.7744 \\
N1P1 & -602307.6421 & 2009661.7173 & -0.30 & 0.7673 \\
N1P1+FYM1 & -870015.4579 & 2009661.7173 & -0.43 & 0.6695 \\
N1P1+FYM1+R & -1271214.6500 & 2009380.4688 & -0.63 & 0.5338 \\
N1P1+R & -2041483.3921 & 2009661.7173 & -1.02 & 0.3213 \\
NIL & -583133.2079 & 2009661.7173 & -0.29 & 0.7745 \\
NIL+R & -2818243.1500 & 2009380.4688 & -1.40 & 0.1754 \\
BlockII & 750926.6000 & 3101860.4755 & 0.24 & 0.8111 \\
BlockIII & -655484.4316 & 3104774.3892 & -0.21 & 0.8348 \\
BlockIV & 542267.8316 & 3104774.3892 & 0.17 & 0.8630 \\
\hline
\end{tabular}

Appendix IV: Full Model 2 Treatment Factors for Microbial Population ( $\left.y_{2}\right)$

\begin{tabular}{rrrrr}
\hline Parameter & Estimate & Std. Error & $\mathrm{t}$ value & $\operatorname{Pr}(>|\mathrm{t}|)$ \\
\hline Intercept) & 3966945.0000 & 2911982.4700 & 1.36 & 0.2153 \\
FYM1+R & -2859536.0000 & 4118165.1024 & -0.69 & 0.5098 \\
N1P1 & 723679.0000 & 4118165.1024 & 0.18 & 0.8655 \\
N1P1+FYM1 & -2725349.5000 & 3566435.5957 & -0.76 & 0.4697 \\
N1P1+FYM1+R & -6144462.0000 & 4118165.1024 & -1.49 & 0.1793 \\
N1P1+R & -6047450.0000 & 4118165.1024 & -1.47 & 0.1854 \\
NIL & -5641030.0000 & 3566435.5957 & -1.58 & 0.1577 \\
NIL+R & -5986798.0000 & 4118165.1024 & -1.45 & 0.1893 \\
BlockII & -1933865.0000 & 4118165.1024 & -0.47 & 0.6529 \\
BlockIII & -769801.0000 & 4118165.1024 & -0.19 & 0.8570 \\
BlockIV & 3341376.0000 & 4118165.1024 & 0.81 & 0.4439 \\
N1P1:BlockII & 7013594.0000 & 5447820.3594 & 1.29 & $0.0238^{*}$ \\
N1P1+FYM1:BlockII & 3340852.5000 & 5447820.3594 & 0.61 & 0.5591 \\
N1P1+FYM1+R:BlockII & 8176981.5000 & 5447820.3594 & 1.50 & 0.1771 \\
N1P1+R:BlockII & 5637904.0000 & 5823964.9399 & 0.97 & 0.3653 \\
NIL:BlockII & 11632650.0000 & 5447820.3594 & 2.14 & $0.0701^{*}$ \\
NIL+R:BlockII & 5272073.5000 & 5447820.3594 & 0.97 & 0.3654 \\
FYM1+R:BlockIII & 2428955.0000 & 5823964.9399 & 0.42 & 0.6891 \\
N1P1:BlockIII & -2874062.0000 & 5447820.3594 & -0.53 & 0.6141 \\
N1P1+FYM1:BlockIII & 1281375.5000 & 5447820.3594 & 0.24 & 0.8208 \\
N1P1+FYM1+R:BlockIII & 5823818.0000 & 5823964.9399 & 1.00 & 0.3506 \\
N1P1+R:BlockIII & 5250139.5000 & 5447820.3594 & 0.96 & 0.3673 \\
NIL:BlockIII & 5799829.0000 & 5447820.3594 & 1.06 & 0.3224 \\
NIL+R:BlockIII & 4814864.0000 & 5823964.9399 & 0.83 & 0.4357 \\
\hline & & & &
\end{tabular}




\section{References}

[1] Box, G., \& Wilson, K. (1951). On the experimental attainment of optimum conditions. Journal of the Royal Statistical Society, Series B, 13 (1), 1-45.

[2] Cheng, S.-W., \& Wu, C. F. (2001). Factor screening and response surface exploration. Statistica Sinaca, 553-604.

[3] Cochran, W. G., \& Cox, G. M. (1950). Experimental Designs. New York: Wiley.

[4] Edmondson, R. N. (1991). Agricultural response surface experiments based on four level-factorial designs. Biometrics, 1435-1448.

[5] Food and Agriculture Organization for United Nation. (2012). The state of food insecurity in the world. Rome: United Nations.

[6] Food and Agriculture for United Nation. (2014). The state of food insecurity in the world. Rome: United Nation.

[7] Food and Agriculture Organization for United Nation. (2013). The state of food and agriculture. Rome: United Nation.

[8] Food and Agriculture Organization of the United Nation. (2015). The State of Food and Agriculture Report 2015: Social protection and agriculture: breaking the cycle of rural poverty. Rome: United Nation.

[9] George, E. P., Hunter, J. S., \& Hunter, W. G. (2005). Statistics for experinters: Design, innovation and discovery 2 nd edition.

[10] Greenland, D. (1994). Soil science and sustainable land management. Soil science and sustainable land management in the tropics, 1-15.

[11] Hill, W. J., \& Hunter, W. G. (1966). A review of response surface methodology-a literature survey. Techno Metric, 8, 571-590.

[12] Kariuki, J. G. (2011). The future of agriculture in Africa (The Pardee Paper No. 15). Boston: Boston University.

[13] Kenya National Bureau of Statistics. (2016). Economic survey. Nairobi: Government of Kenya.

[14] Kibunja, C. N. (2007). Nutrient dynamics and soil microbial diversity (Unpublished PhD Thesis). Nairobi: University of Nairobi.
[15] Koning, N., \& Smaling, E. (2005). Environmental crisis or "lie of land?" The debate on soil degradation in Africa. Land Use Policy, 22, 3-11.

[16] Lee, J.-K., Park, I., Choo, S., Kim, S., Choi, Y., \& Choo, J. (2013). Optimization of medium composition for alphagalactosidase production by Antarctica bacterial isolate, Bacillus sp. LX-1 using response surface methodology. African Journal of Microbiology Research, 7(27), 3494-3500.

[17] Maat, H. (2011). The history and future of agricultural experiments. NJAS - WageningenJournal of Life Sciences, 57, 187-195.

[18] Mead, R., \& Pike, D. J. (1975). A review of response surface methodology from a biometric point of view. Biometric, 803915 .

[19] Montgomery, D. C. (2009). In Design and anlysis of experiments. New York: John Wiley \& Sons.

[20] Montgomery, D. C. (2009). Design and analysis of experiments. New York: John Wiley \& Sons.

[21] Myer, R. H., \& Montgomery, D. C. (2002). Response surface methodology: process and product optimization using designed experiments, second edn,. Boston: PSN-Kent.

[22] Myer, R. H., Khuri, A. I., \& Carter, W. H. (1989). Response surface methodology. Technometrics, 31(2), 137-157.

[23] Raissi, S., \& Farsani, R. (2009). Statistical Process Optimization Through Multi-Response Surface Methodology. World Academy of Science, Engineering and Technology, 267-271.

[24] Richards, P. (1989). Farmers also experiment: a neglected intellectual resource in African science. Quality and Reliability Engineering International, 3, 227-240.

[25] Su, C.-T., \& Yeh, C.-J. (2011). Optimization of the CU wire bonding process for IC assembly using Taguchi methods. Microelectronics reliability, 53-59.

[26] Wadsworth, H. M. (1997). Handbook of statistical methods for engineers and scientists. (2nd, Ed.) New York: McGraw - Hill Professional.

[27] Wass, J. (2010). First steps in experimental design-the screening experiment. Journal of validation technology, 49-57. 